\title{
SISTEMAS, ESTEREOTIPOS Y SINGULARIDADES EN PSICOTERAPIA ENTREVISTA A MARCELO PAKMAN
}

\author{
Fabiola Inés Arellano Jiménez \\ Universidad Nacional Autónoma de México \\ México
}

Marcelo Pakman, médico, conferencista internacional, invitado por instituciones y universidades de Norte y Sudamérica, Europa y Asia, es conocido por sus articulaciones entre filosofía, epistemología, arte y pensamiento crítico con la práctica clínica de la psicoterapia, la terapia familiar y las intervenciones sociales en ámbitos diversos.

Autor de Palabras que permanecen, palabras por venir: micropolítica y poética en psicoterapia (2011); y de los dos primeros volúmenes de la trilogía "El espectro y el signo": Texturas de la imaginación (2014) y El sentido de lo justo (2018), que elaboran una posición crítico poética integradora de una búsqueda ética a partir de una micropolitica de la vida cotidiana y de eventos poéticos transformativos. Recién publicado en Julio de 2020, A flor de piel. Pensar la pandemia, todos por Editorial Gedisa.

\section{ENTREVISTA REALIZADA POR}

Fabiola Arellano, maestra en psicología por la Facultad de Estudios Superiores Iztacala de la Universidad Nacional Autónoma de México. Ponente, docente, psicoterapeuta y coeditora de la revista Salutare. Entre sus trabajos se encuentran: Psicosis y arte, bordeando un yo exiliado de sí mismo; y Perspectivas en psicoterapia, caracterización de personajes.

\section{Presentación de LA ENTREVISTA}

Entrevisté a Marcelo Pakman en su visita a México en noviembre de 2019. Fue una entrevista de una hora y media de duración, teniendo como objetivos ahondar en lo que él nombra postura crítica-poética. Posterior a la transcripción, Pakman hizo la revisión de la misma para editar lo necesario para que la información fuese clara.

\section{Bitácora del ARTículo:}

| Recibido: 19 de Septiembre de 2019 | Aceptado: 23 Octubre de 2019 | Publicado en línea: Enero - Junio de 2020 |

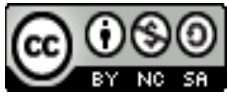

Copyright: (C) 2020 Arellano-Jiménez, F.I.

Este es un artículo de acceso abierto distribuido bajo los términos de la licencia Creative Commons Reconocimiento-NoComercial 4.0 Internacional, por lo que su contenido gráfico y escrito se puede compartir, copiar y redistribuir total o parcialmente sin necesidad de permiso expreso de sus autora con la única condición de que no se puede usar con fines directamente comerciales y los términos legales de cualquier trabajo derivado deben ser los mismos que se expresan en la presente declaración. La única condición es que se cite la fuente con referencia a la Revista Digital Internacional de Psicología y Ciencia Social y a su autora. 


\section{INTRODUCCIÓN}

H ablar con el que escribe, le da una dimensión distinta a las letras. Quizá porque el que habla ya no es el mismo del relato. Tal vez nunca lo fue. Esta es una búsqueda por indagar la propuesta de Pakman tomando su mano y no sólo sus letras.

Fabiola Arellano: ¿Qué te motivó a escribir?

Marcelo Pakman: Sentía que necesitaba un lugar para indagar más a fondo cosas que venía elaborando, pero que quedaban como flashes desarticulados al dar presentaciones en seminarios, conferencias o participaciones en mesas redondas sobre práctica clínica, que es mi punto de partida cotidiano. Al articularlo de manera más precisa para escribirlo pude entender más hacia dónde estaba yendo en términos de un movimiento más amplio, y lo que vi es que se esbozaba un proyecto relacionado con el juego de los sistemas con momentos de singularidad entendida como una capacidad potencial que no está garantizada de expresarse nece"... El espectro de la realidad nunca desaparece; está todo el tiempo embrujando a la ficción, almundo de signos entendidos en general como de significados en el que vivimos..." sariamente en, por ejemplo, una narrativa. $Y$ estos temas centrales, sistema y singularidad, se vinculaban de modos diversos y con toda una serie de cuestiones conceptuales, como la de las micropolíticas dominantes, los estereotipos y la domesticación que la repetición implica, así como los eventos en particular poéticos, como comencé a llamarlo para no quedar capturados en eso, la cuestión del sujeto y del existente, las imágenes y la imaginación, y muchos otros. No se trataba de que quisiera hacer un sistema completo que diera cuenta de todo sino de hacer una reflexión sobre esas cuestiones en la psicoterapia, pero que desborda más allá de la misma. Contribuyó también que al estar menos ocupado con hacer clínica pude hacer más tiempo para escribir.

Fabiola Arellano: ¿Qué tanto la psicoterapia podría parecerse a un relato de ensoñación, cargado de ficción, algo más parecido a la literatura que al caso clínico relatado al que estamos tan habituados? Con esto también me refiero a tus libros, en los que he encontrado cuando menos a tres Marcelos diferentes; ¿qué tanto logras reconocerte en estos libros que también experimentan las transformaciones del tiempo?

Marcelo Pakman: El primer libro que salió en 2011, Palabras que permanecen, palabras por venir (GEDISA), es un trabajo transicional; en él esbozaba las ideas que, más elaboradas, exploré en la trilogía que está en curso, con el título El espectro y el signo, de la que salieron ya los dos primeros volúmenes: Texturas de la imaginación (GEDISA, 2014) y El sentido de lo justo (GEDISA, 2018), un movimiento hacia la revaluación de la realidad y la verdad, conceptos desvalorizados en la segunda mitad del siglo XX; en el contexto del giro lingüístico cada vez me interesó más. La ficción a la que te referías es parte de las cosas que existen, ya que incluso si se tratara de la ficción más pura, conserva texturas de lo real que uno reconoce y que son en las que uno vive, así como en el sueño puede haber seres fantásticos que aparecen, pero con elementos del mundo de la vigilia, ése que nos encuentra al despertar. Creo que me fui moviendo cada vez más hacia comprender la transformación subjetiva que uno hace de la realidad y que por supuesto todavía tiene mucho de una realidad que excede al trabajo de ficcionalización, lo cual no quiere decir que esa realidad sea algo evidente y directamente captado como datos de los sentidos, sino que requiere ser comprendida y allí juega un papel importante el concepto de sentido que no es el dato empírico de una realidad inanimada ni el mundo del significado verbal, reflexivo. El espectro de la realidad nunca desaparece; está todo el tiempo embrujando a la ficción, al mundo de signos entendidos en general como de significados en el que vivimos. Esta concepción es diferente al pensamiento habitual sobre los espectros vistos como algo diáfano, algo transparente que embruja a las cosas materiales. Lo que ocurre es que estamos tan dentro de este mundo de signos entendidos como significados que lo que embruja a los signos es la materialidad de las cosas, la sensualidad textural de las cosas de la que no podemos terminar de desprendernos.

Fabiola Arellano: ¿Editarías o eliminarías algo de lo que ya está escrito?

Marcelo Pakman: Probablemente. Siempre que releo algo me parece que hay algo que no está bien dicho o que hay frases desgraciadas o cosas confusas. Creo que de a poco voy aprendiendo a decirlo un poco más precisamente. Mi estilo es el de dar vueltas, cercar los conceptos, ir para adelante e ir para 
atrás como lo hace el mar en la playa, y así es como escribo. No es que lo recomiende; así me sale.

Fabiola Arellano: ¿Te preocupan los lectores cuando escribes?

Marcelo Pakman: Los lectores, como es de esperar, pendulan entre los que leen lo que ya saben que les suena entonces parecido y los otros que leen algo que no habían pensado antes y se entusiasman al vislumbrar una apertura de un modo de trabajo o algo novedoso en relación con la clínica o con el modo de encarar un concepto. Por cierto que los segundos son más gratificantes para mí, pero los primeros me llevan a trabajar en decir lo que pienso quizás un poco mejor y así lograr que más gente se sienta tocada ante esto $y$, aunque sea medio descorazonador cuando algunos afirman que yo digo algo y no lo he dicho, después de ese momento de bajón viene el esfuerzo por decirlo más claramente. Así que ambos tipos de lectores son útiles para mí. A lo largo del tiempo va sirviéndome repetirme y cambiarme para dar lugar a otras cosas; voy incorporando cosas que al principio no eran importantes en aquel primer libro como el tema de lo real que llegó a parecer poco interesante, en el siglo $X X$, ante el interés que despertaba pensar que todo era un gran texto.

Fabiola Arellano: ¿De qué formas crees que podría generarse una especie de reporte clínico que no esté tan descarnado, tan muerto, tan formateado? Lo pregunto porque cuando te he escuchado abordas los casos clínicos desde un lugar poco habitual pero continúo, encontrándome que en la práctica docente se perpetúan los guiones desde sus formatos, instructivos y formularios, en los que permitimos que se nos escapen muchas cosas.

Marcelo Pakman: Tendría sus problemas también encontrar eso que sugieres porque uno trabaja dentro de una tradición, así que primero uno no puede elegir tanto; segundo, tiene que haber un punto de partida desde donde uno está hablando. El motivo de consulta, el problema, todo ese formato todavía vigente en la mayoría de las instituciones, más temprano que tarde está allí, pero uno puede tomar lo mínimo necesario para a partir de ahí empezar a transgredir un poco las fronteras. Esto no quiere decir que el surgimiento de lo nuevo sea sólo reactivo a esas domesticaciones, ya que tiene también su propia originalidad.

Fabiola Arellano: Tú dices aprender y luego transgredir.

Marcelo Pakman: Sí; en la práctica es así. No partimos de una especie de no lugar con libertad absoluta; partimos de una universidad en la que estudiamos, de una institución en la que trabajamos; hablamos con gente con la que usamos las palabras que circulan y que hay que usar. Partimos de eso. El asunto es no quedar totalmente capturados en eso y tratar de estirar los bordes para ganar en libertad, que aunque siempre es libertad condicional es mejor que ninguna libertad. No se puede empezar en el desorden total. A veces alguna gente ha tomado lo que yo estoy diciendo como una especie de discurso contra todo orden, contra todo método, y como una especie de permiso para no tener que estudiar y usar todo lo que sale de la interioridad, la intuición y lo emocional, como un permiso para decir que todo vale, cuando en verdad yo no estoy diciendo eso. Lo que yo estoy diciendo es que incluso la "interioridad" está for- de no lugar con libertad absoluta; partimos de una universidad en la que estudiamos, de una institución en la que trabajamos; hablamos con gente con la que usamos las palabras que circulan y que hay que usar. Partimos de eso. El asunto es no quedar totalmente capturados en eso y tratar de estirar los bordes para ganar en libertad, que aunque siempre es libertad condicional es mejor que ninguna libertad... sea a veces, que se puede ganar.

Fabiola Arellano: A mí lo que no me gusta es que uno se termina acomodando a los espacios ya escritos.

Marcelo Pakman: Pero no hablas desde otro planeta, así que no es que te acomodes, ya hablas, para empezar y hasta cierto punto, desde el acomodo, y es a partir de ahí que empiezas a maniobrar para ir ganando grados de libertad que son sumamente novedosos y que dan lugar a veces a eventos poéticos.

Fabiola Arellano: No sé si me gane el pesimismo al pensar que aunque hay momentos excepcionales luego se vuelven parte de lo que ya permanecía.

Marcelo Pakman: Esa es siempre una posibilidad, pero está el desafío de sostener lo que tienen esos momentos, o más bien eventos, porque no son puntuales, de novedoso para que ese re-englobamiento pase lo menos posible. Además hay que tener en cuenta que el pesimismo recorre muchas micropolíticas dominantes; es parte de afirmar que no hay que hacer ningún esfuerzo porque 
de nada servirá, y es un mensaje muy terrible porque lo que puede haber de apertura queda totalmente cerrado con esa noción triste que era un tema que le preocupaba a Spinoza. Yo creo que de algún modo vislumbraba que había en eso algo muy negativo para la cuestión de la libertad; él era muy consciente de cómo las causalidades no dejan demasiado espacio.

Fabiola Arellano: ¿Podrías explicar o describir qué es lo que le pasa a esos psicoterapeutas que están muy cómodos con una forma descarnada de hablar y de habitar la psicoterapia?

Marcelo Pakman: Creo que en ese caso hay una insatisfacción al mismo tiempo. Yo no me creo demasiado la tranquilidad o la satisfacción de estar dentro de las estructuras. Por ejemplo, al supervisar uno se da cuenta que hay siempre una infelicidad porque hay un elemento común que reaparece. Los terapeutas de algún modo afirman que sienten que no logran ser terapeutas al trabajar en un sistema que tiene algo de obsceno al exigirles que lo sean sin poder serlo, y el ejemplo de eso es que se sienten presionados por aspectos tanto explícitos como implícitos de ese sistema. Hay una queja siempre que se habla de la insatisfacción y de la imposibilidad de ser como les gustaría. ¿En qué podemos notarlo? En que los terapeutas tienen secretos, tienen cosas que pueden decir a sus colegas pero no a sus pacientes, o que se las pueden decir a sí mismos pero no a sus colegas ni a sus pacientes, y a veces son tan secretas que no se las pueden decir ni a sí mismos.

Fabiola Arellano: Hay algo que te he escuchado decir en repetidas ocasiones, y cada vez que lo oigo se me retuerce el estómago: educar la sensibilidad. Pienso que es un oxímoron porque pienso que la sensibilidad y la educación no pueden juntarse.

Marcelo Pakman: El problema es que justamente educar la sensibilidad es algo que ya pasa también desde que crecemos, pero con mucha frecuencia sucede como una educación para el estereotipo de la sensibilidad. El asunto consiste, como en todas las otras educaciones, en cómo uno se las puede arreglar para que la interacción con otros se dé en torno a singularidades, elementos únicos e irrepetibles que nos tocan, y a partir de allí que esas singularidades puedan vivirse juntas desde el distanciamiento de los estereotipos haciendo posible la aparición de otra sensibilidad, esa que todavía se puede sustraer en alguna medida de esos estereotipos, de manera que pueda decir otra cosa de uno mismo y de lo que es estar en este mundo.

Fabiola Arellano: Te he pensado como alguien que teje diversos elementos y luego habla de ellos. ¿Qué po- drías decir acerca de la configuración de tu identidad como psicoterapeuta?

Marcelo Pakman: Creo que es algo así como el caso de Penélope, alguien que va tejiendo y destejiendo para escapar de las leyes que no le gustan y que pretenden educar su sensibilidad, que es un poco lo que hacemos todos en esas normas que nos gustan en parte y que no nos gustan del todo porque acallan una parte de nuestra sensibilidad, aunque con frecuencia eso no esté claro ni para nosotros mismos a un nivel reflexivo. Así que en los buenos días tiene que ver con tejer y destejer, y en los malos días en los que puedo estar cansado o no particularmente ocurrente, o incluso demasiado restringido por situaciones diversas; se trata más de cumplir con la huella de lo ya hecho que también sirve a veces, y es lo que uno llama el oficio, incluyendo ese tejer y destejer desde lo que uno ya sabe.

Fabiola Arellano: Si que el que habla y el que vive no son el mismo, como dice Agamben, entonces, ¿quién es el que vive?

Marcelo Pakman: Agamben dice algo más: aquí en habla y quien vive, a pesar de no ser el mismo, no pueden dejar de estar en relación el uno con el otro. Desde el momento en que entramos en el habla se produce una disyunción, pero al mismo tiempo no hay una desconección total, lo que quiere decir que a pesar de quién habla, todavía podemos encontrar al que vive, aunque no sea en todo momento. La escritura plantea problemas aparte porque tiene su propia materialidad y su propia tendencia a desconectarse y a conectarse de la vida. Ahora está un poco de moda hablar de lo narrativo en desmedro de hablar de lo literario, o dándolos como sinónimos. A mí me sigue gustando más hablar de la literatura porque tiene una tradición importante de no perder la conexión con lo viviente. a diferencia de lo narrativo, que se transformó, dentro del giro lingüístico, en un modo de mirar lo literario, pero también de desvirtuarlo. En el campo de la psicoterapia cayó en el estereotipo y la repetición. Aunque se supone que lo narrativo intentaba salir del estereotipo y recuperar lo que era único en la vida de las personas, ha fracasado con frecuencia en eso, porque las narrativas que uno oye en el campo de la terapia, sospechosamente se parecen mucho las unas a las otras. Lo que pasa es que la gente viene a la terapia ya un poco narrativizada, un poco estereotipada y pareciéndose los unos a los otros, diciendo cosas muy parecidas; basta salir a la calle y escuchar a las personas. Uno muy rápidamente se entera de qué van las conversaciones, y eso 
quiere decir que justamente está todo el proceso muy estereotipado.

Fabiola Arellano: Y sabemos de qué se habla porque somos parte de eso.

Marcelo Pakman: Justamente. Ese es el juego permanente y está bien Ilamarlo el juego de Penélope.

Fabiola Arellano: Cuando se conoce al autor de determinada obra se experimenta una especie de atajo para conocer al que vive.

Marcelo Pakman: Mucha gente ha recomendado lo conconectar lo escrito con la vida del autor nos negamos a matarlo como habría que hacerlo, para después recordar simplemente las palabras desde esa postura. Pienso que es bueno matar al autor siempre y cuando no se mate con el autor a todo lo viviente que hay ahí, es decir, matarlo pero no matar a lo vivo del autor y dejar que aparezca la vida que es lo que es en sí misma, ya que no es símbolo de otra cosa. Reconocer la vida siempre revitaliza, como cuando uno dice "tomemos agua fresca" y no hace falta explicar porqué, ya que entendemos que el agua fresca revimentos de agua fresca de la vida; son las más bonitas.

Fabiola Arellano: Si dentro de 60 años existieran personas intentando contabilizar los "...Pienso que es bueno matar al autor siempre y cuando no se mate con el autor a todo lo viviente que hay ahí, es decir, matarlo pero no matar a lo vivo del autor $y$ dejar que aparezca la vida que es lo que es en sí misma,

ya que no es símbolo de otra cosa. ... no está tan mal. trario: ¡que muera el autor! Pero de algún modo al retaliza. Las palabras que çn una extensión de los mo-

no son universitarias, y un poco como mercenario voy a donde me inviten asumiendo que siempre habrá gente interesada por oír lo que tengo que decir, aparte de que tengo que vivir de algo y vivir de eso

Fabiola Arellano: Pienso que la psicoterapia se queda corta a la hora de pensar en las problemáticas sociales. Muchas veces siento como algo aislado y limitante el lugar del terapeuta. ¿Tú crees que tiene más alcances de los que yo estoy alcanzando a ver?

Marcelo Pakman: Reconozco que puede ser difícil encontrar espacios en los que uno pueda poner esto que estamos diciendo, todas estas inquietudes que venimos hablando. También la psicoterapia no es muy antigua como actividad humana salvo que uno diga que hay antecedentes que están relacionados con ir a consultar oráculos, gurúes o a confesarse, pero como psicoterapia llevamos poco más de 100 años y quizá va a ser remplazada por otro tipo de cosas. Tampoco estamos seguros ni sabemos con qué va a ser remplazada, así que por ahora es un espacio que hay en donde la gente lleva y problematiza sus vidas, y es difícil ahora hacer una cosa completamente diferente porque no sabemos ni cómo pensarla. biola Arellano: Desde tu punto de vista, ¿cuáles son las problemáticas sociales más importantes en la actualidad?

eventos poéticos y haciendo casi que de la práctica el evento poético en sí mismo, ¿qué opinión tendrías al respecto?

Marcelo Pakman: No sé cómo sería en 60 años, pero por lo pronto suena mal, muy parecido a Bateson desesperado porque la gente estaba contando dobles vínculos.

Fabiola Arellano: Suena a una pesadilla.

Marcelo Pakman: Pero al mismo tiempo uno no puede ser el policía de todo lo que la gente saca de lo que uno dice o quisiera decir; uno puede tratar de ser el policía; sin embargo, mientras uno está vivo se puede volver a aclarar lo que uno quería decir.

Fabiola Arellano: Cuando uno ya está muerto, ese ya no es un problema.

Marcelo Pakman: Quizá haya otros problemas, pero no ese.

Fabiola Arellano: ¿Qué tan bien recibida ha sido tu propuesta en la academia a lo largo de estos años?

Marcelo Pakman: Yo no he tenido una vida académica. Me contactan en universidades o en instituciones que
Marcelo Pakman: Las problemáticas concretas por las que las personas se están preocupando, por las que buscan ayuda y que son las que están a la vista. La gente se está matando porque está harta de muchas cosas; los adolescentes se están matando con mucha frecuencia; por ejemplo, en Estados Unidos hay drogas que más que entretenimientos parecen condenas. Hay violencias de todo tipo, muy mezcladas con las instituciones que tenemos, desde el matrimonio hasta el empleo. Las sociedades las hemos ido armando y no ha sido del todo voluntariamente, ya que no es que a cada uno de nosotros se nos preguntó si estábamos de acuerdo con el capitalismo. Las problemáticas están cada vez más a la vista y es cierto que es un avance que algunas sean más visibles que antes, pero también es cierto que hay una especie de cinismo cultural que lleva a que el hecho de que algo se haga visible no signifique su solución inmediata. Ahí empieza otro escalón de la historia; nombrar las cosas no es suficiente.

Fabiola Arellano: ¿Qué tendría que pasar para que la perspectiva crítico-poética pierda vigencia? 
Marcelo Pakman: Todavía no la tiene porque por ahora no es una perspectiva dominante, un polo atractor novedoso para que me tenga que preocupar por eso.

Fabiola Arellano: Pienso que la mayoría de los psicoterapeutas somos una especie de máquinas estereotipantes. ¿Tú crees que esto ha sido diferente a lo largo de la historia de la psicoterapia?

Marcelo Pakman: Es posible que haya ahora una especie de multiplicación del estereotipo que antes no tenía posibilidad de desarrollarse así porque todo se extiende con mucha rapidez ahora; entonces es posible que haya ahora una aceleración, así como la hay en muchas otras cosas. Estamos sentados aquí en la Ciudad de México, vemos enfrente un centro de compras; si no nos dicen que es la Ciudad de México podría ser un montón de otras ciudades. Cuando viajo hay momentos en los que me despierto y no me acuerdo dónde estoy, y sé que es cuestión de esperar unos segundos y recordar algo que me diga donde estoy, pero en parte también tiene que ver con este fenómeno de la repetición, de lo parecido tan terrible, y hay muchos que se han dedicado a hablar de este no lugar que las cosas tienen porque justamente faltan señales de singularidad, y el problema es que algunos celebraron esta concepción del simulacro donde ya se pensaba que no había originales, como si fuera un avance. Parte del problema también es el intento de contrarrestar ese fenómeno con un culturalismo a ultranza, como si al ir al centro de compras vestidos con nuestros trajes tradicionales de nuestras tribus fuera suficiente para salvarnos. No es tan fácil, porque esas señales culturales pueden hablar a veces de una tradición que no se mueve, lo cual relativiza esa idealización de lo cultural, como si nos fuese a salvar al permitirnos recuperar lo único y diferente. También es interesante entones tener un lugar desde donde criticar algunas tradiciones culturales que no porque lo sean se tendrían que aceptar como fantásticas. Por ejemplo, en estos días hubo mucha discusión en torno a los sucesos de Bolivia, donde lo que empezó como excesos antidemocráticos de un presidente que por otra parte había favorecido a grupos indígenas de los que él proviene, terminó con lo que está pareciendo un golpe típico de derecha con sus violencias. Al mismo tiempo, hace un par de días Rita Segato alertaba contra no polarizar la discusión. No se trataba de tomar una actitud antifascista, antigolpe, o tomar una actitud antiEvo Morales. Rita Segato alertaba contra no hacer una crítica demasiado suave. Ella recordaba desde su preocupación por el feminismo y por las cuestiones de género que un día Evo dijo en un reportaje: "yo con mi charango, mi coca y una quinceañera ya estoy bien". Ella decía que incluso si fuese un chiste, sería uno muy malo y que habría que tomarlo muy seriamente, y más aún viniendo de un presidente supuestamente progresista. Entonces hay una complejidad antipureza de ponerse totalmente a favor de este o aquel, y que por supuesto es importante como ejercicio intelectual y político.

Fabiola Arellano: Alguna vez tú comentaste que hacías algo diferente a la terapia breve centrada en soluciones o estas fórmulas empleadas en psicoterapia. ¿Qué otras cosas te niegas a hacer con la psicoterapia?

Marcelo Pakman: Alguien me preguntó cómo me ubicaba respecto a la psicoterapia breve, y yo había dicho que nunca había definido mi práctica para empezar basado en un modelo. La terapia breve y sus 10 o X sesiones no es algo que pueda definir lo que yo hago ni quiero estar obligado por una cierta duración; no quiero estar preocupado por tener que terminar en un tiempo determinado. Entonces elegí no meterme en una camisa de fuerza que definiera mi práctica clínica, así como no me gusta definir a mi terapia, y que no creo que lo sea, como colaborativa, porque no creo que siempre pueda sostener la actitud colaborativa porque no va con mi estilo ni con mi pensamiento; entonces hay ciertas cosas en las que es bueno no meterse porque uno sabe que le van a traer problemas. Yo no puedo definir el tipo de terapia que me gusta hacer y que me sale, y que les gusta a los que están trabajando conmigo, ni en términos de duración ni de estilo comunicacional, porque a veces soy colaborativo y a veces confrontativo, y no está allí lo definitorio de mi trabajo. Yo hablo de tener una posición crítica, pero crítica no significa afirmar que todo está mal, sino de tratar de distinguir que siempre las cosas vienen mezcladas y no son blancas ni negras. Pienso que casi siempre lo que hago entra en ser crítico, y también en la poética, al tener una sensibilidad ante lo que va a apareciendo y que no sabemos a dónde nos lleva. De ahí que cuando tengo que hablar de lo que hago, lo presento y lo trabajo a través de los conceptos de micropolíticas dominantes, de repetición y estereotipo como atractores poderosos que nos reclutan como agentes de esas fuerzas, de la posibilidad de alejarnos de esas posiciones dando lugar, a partir de ciertos puntos de resistencia, a eventos poéticos en que aparecen fenómenos de sentido singulares y a la necesidad de integrar esos eventos a través de un trabajo de la imaginación que consolida la aparición de un nuevo movimiento, que es también ético hacia una vida mejor, que valga la pena de ser vivida. 